\title{
A Reconfiguração Automotiva E SEUS IM PACTOS ESPACIAIS: uma Análise do Caso Brasileiro
}

\author{
Marcus Alban*
}

RESUM O

as décadas recentes a implantação dos complexos automotivos, em todo o mundo, tem fugido ao velho padrão de polarização em uma única região por nação. Para muitos analistas, esse é um processo que decorre de uma crescente guerra fiscal entre as instâncias sub-nacionais, o que levaria a decisões locacionais de baixa racionalidade. Essa visão, contudo, conforme a analise desenvolvida, apresenta uma série de fragilidades. De fato, ainda que a guerra fiscal seja patente nessa nova configuração produtiva/espacial, ela parece ser muito mais uma conseqüência do que a causa da mesma. Nesse sentido, as decisões locacionais mantêm-se racionais - ao menos no âmbito das informações disponíveis - mesmo nos casos ditos extremos, como o da opção da Ford pela Bahia para o seu ambicioso Projeto Amazon.

\begin{abstract}
$\mathrm{n}$ the last decades the decision on the allocation of an assembly line complex has not followed the traditional pattern of polarization in only one region. This has been true all over the world. To many analysts, this new trend is a result of an increasing wave of fiscal war between subnational governments, leading to location decisions bounded by low rationality. This argument, however, has several limitations, as discussed in this article. I argue that although a fiscal war is part of this new productive/spatial arrangement, it is more a result than the cause of the process. Following this line of reasoning, location decisions carry on being rational, at least under current available information, even in cases labeled as extreme examples, such as the option made by Ford to locate in the state of Bahia its ambitious Amazon Project.
\end{abstract}




\section{A Reconfiguração Produtiva}

urgindo na virada do século XIX para o século $X X$, a indústria automotiva teve de enfrentar, como nenhuma outra, os graves gargalos da montagem artesanal. Com um bem muito complexo, produzido a partir de uma infinida de de peças de baixa precisão, ela implicava em longas jornadas de mecânicos ajustadores, o que resultava em produtos extremamente caros. O potencial de mercado para um automóvel mais barato era, porém, imenso. De outro lado, nos sistemas fabris processava-se, nesse mesmo período, a substituição do vapor pela energia elétrica, o que criava a possibilidade de peças mais precisas. Ou seja, se as dificuldades da montagem artesanal eram enormes, havia também as condições econômicas e técnicas para a sua superação e assim se deu. ${ }^{1}$

Como se sabe, foi Henry Ford quem concebeu e implementou a superação da montagem artesanal. Sendo um excelente mecânico e havendo trabalhado na indústria elétrica, Ford percebia a necessidade e a possibilidade da fabricação de peças mais precisas. Dessa maneira, ao fundar a Ford Motor Company, em 1903, inicia um intenso processo de padronização que irá culminar com a opção pelo modelo único, o famoso Ford $\mathrm{T}$, em 1908. Com o modelo único e peças de maior precisão, obtidas por processos eletromecânicos, Ford elimina a necessidade do ajustamento entre as partes, fazendo com que quase toda a montagem pudesse ser taylorizada e, logo, operada por mecânicos de baixa qualificação.

Mesmo mantendo os carros fixos, o que levava os mecânicos e as peças a se deslocarem por entre as plataformas, os ganhos de produtividade com a eliminação do ajustamento foram intensos o bastante para permitir expressivas e sucessivas reduções de preços. Com os novos preços, Ford aumentou de tal maneira a demanda por automóveis que foi levado a construir uma nova e mais ampla planta de montagem (Tabela 1). Nesta, inaugurada em 1911, para enfrentar o enorme e complexo fluxo de materiais pela fábrica, desenvolve-se, então, a revolucionária linha de montagem. Com a mesma, os mecânicos e as peças passaram a se localizar em unidades de trabalho fixas, racionalmente dispostas ao longo das linhas por onde se deslocavam os itens e conjuntos em montagem.

Ao eliminar os tempos de deslocamento dos trabalhadores e materiais pela fábrica, a linha de montagem possibilitou expressivos ganhos instantâneos de produtividade, que ampliaram ainda mais a vantagem competitiva da Ford. Mais importante que eles, no entanto, foram os ganhos dinâmicos de longo prazo. Ocorre que, com a fixação das estações de trabalho, tornou-se possível avançar com a taylorização, numa divisão do trabalho muito mais intensa. Paralelamente, com a flexibilidade da energia elétrica, possibilitou-se também o gradativo avanço da mecanização na própria montagem. Assim, não só mecanizou-se o operário, como, em muitas operações, substituíram-se os mesmos por máquinas dedicadas.

Tabela 1 Desempenho Operacional da Ford Motor Company, 1909 - 1921 Período Preço em US\$ Produção Faturamento Estimado US\$

\begin{tabular}{lcrc} 
& & & \multicolumn{1}{c}{ mil } \\
\hline $1909-1910$ & 950 & 18.664 & 17.731 \\
$1910-1911$ & 780 & 34.528 & 26.932 \\
$1911-1912$ & 690 & 78.440 & 54.124 \\
$1912-1913$ & 600 & 168.220 & 100.932 \\
$1913-1914$ & 550 & 248.307 & 136.568 \\
$1914-1915$ & 490 & 308.213 & 150.044 \\
$1915-1916$ & 440 & 533.921 & 234.925 \\
$1916-1917$ & 360 & 785.432 & 282.755 \\
$1917-1918 *$ & 450 & 706.584 & 317.962 \\
$1918-1919 *$ & 525 & 533.706 & 280.196 \\
$1919-1920$ & $575-440$ & 996.660 & 498.330 \\
$1920-1921$ & $440-355$ & 1.250 .000 & 496.875 \\
\hline
\end{tabular}

Fonte: Ford (1954:115)

Obs.: * Anos de guerra, em que a fábrica operou parcialmente para fins militares.

${ }^{1}$ A análise histórica desenvolvida a seguir, salvo referência em contrário, baseia-se nos clássicos trabalhos de Ford (1954) e Womack, Jones e Ross (1992). 
Deve-se notar que em todo esse processo de superação da montagem artesanal, os ganhos de produtividade estão, direta ou indiretamente, sempre associados à exploração de escalas e rigidez crescentes. Ou seja, a produtividade só se amplia com capacidades produtivas dedicadas e crescentes. Com a eletromecanização das linhas, esse vínculo não se rompe, ao contrário, se torna ainda mais intenso. O fato é que a eletromecânica, por suas características intrínsecas, apresenta custos de controles muito altos. Dessa maneira, tenta-se reduzi-los ou diluí-los por meio de grandes equipamentos de automação rígida. ${ }^{2}$

Seguindo o processo acima de maneira estrita, Henry Ford inaugura, em 1927, sua terceira fábrica, voltada para a fabricação do modelo A, sucessor do T, com a capacidade de cinco mil carros/dia. Ainda que obtendo novos ganhos de produtividade, com essa estratégia a Ford passou a enfrentar sérios problemas mercadológicos. Sucede que, a essa altura, o mercado americano já não mais desejava um modelo único. Muitas famílias já tinham o seu Ford T e desejavam um segundo carro mais sofisticado. Outras preferiam um modelo mais simples e assim por diante. É nesse contexto que a General Motors, uma empresa resultante da fusão de cinco outras, irá assumir a liderança da indústria automotiva.

Sob o comando de Alfred Sloan, a GM, detentora de vários modelos, irá desenvolver a estratégia de um carro para cada tipo de família. Deve-se observar que isto não significa o abandono da linha de montagem com peças padronizadas. Ao contrário, essa dinâmica será ainda mais acirrada através do estabelecimento de peças e conjuntos básicos adotados em vários modelos. Nesse sentido, o que a GM faz é introduzir uma certa flexibilidade no sistema de produção em massa fordista. ${ }^{3}$ Esse sistema adaptado, copiado em seguida pela própria Ford, se difundirá, a partir dos anos 40, por quase toda a estrutura produtiva capitalista, estabelecendo-se como paradigma dominante em todos os sistemas de montagem.

Em que pese todo o potencial da produção em massa, ao final dos anos 70, começo dos 80, ela atinge o seu limite em meio a uma grave crise. O problema é que tendo como fonte básica de produtividade a exploração de escalas crescentes, a produção em massa não tinha como avançar em meio à estagflação reinante no período. É nesse contexto que irá se consolidar um novo e revolucionário sistema de produção de origem japonesa. Desenvolvido, em grande medida, pela Toyota Motor Company (e por isso inicialmente denominado de toyotismo), esse sistema é bastante distinto da produção em massa taylorista-fordista. Ocorre que no Japão do pós-guerra, onde ele se desenvolve, não havia grandes mercados para a produção em massa. Ao contrário, mesmo externamente, os mercados disponíveis eram pequenos e incertos.

Em linhas gerais, o toyotismo é um sistema de organização da produção estruturado em quatro vertentes básicas. São elas: a mecanização flexível, a multifuncionalização da mão-de-obra, a qualidade total e o sistema de just in time gerenciamento. A mecanização flexível consiste numa dinâmica inversa à automação rígida. Ou seja, em lugar de se buscar a eliminação de controles, via máquinas dedicadas, busca-se uma crescente flexibilização mecânica, ainda que à custa de controles também crescentes. A multifuncionalização, por sua vez, consiste numa mão-de-obra altamente treinada em várias funções para possibilitar, não só a operação das máquinas flexíveis, como a rápida reconfiguração de todo sistema produtivo, sempre que necessário.

A terceira vertente, a qualidade total, é uma alternativa à qualidade amostral da produção em massa, possibilitada também pela multifuncionalização da mãode-obra. Com ela todos são responsáveis pela qualidade, que passa a ser produzida em níveis cada vez mais elevados. A quarta vertente, que complementa e articula todo o toyotismo, é o sistema just in time de gerenciamento. Como indica o próprio nome, seu objetivo consiste em possibilitar a produção de cada item

\footnotetext{
2 Sobre esse ponto, ver Alban (1999,caps. 4 e 5).

3 O termo produção em massa foi cunhado pelo próprio Ford, em artigo para a Ecyclopedia Britannica (1926).
} 
exatamente no momento em que é demandado. No limite, isso significa que a produção seria imediata e, logo, poderia se dar com estoques zerados. Naturalmente, assim como a qualidade total, esse objetivo é uma meta nunca plenamente alcançável, mas da qual é sempre possível se chegar um pouco mais perto. ${ }^{4}$

Como se constata, o toyotismo acaba sendo exatamente o inverso do fordismo. Nele, a produtividade é buscada com a manutenção e não com a eliminação da flexibilidade. Isso, contudo, não quer dizer que o toyotismo seja em si um sistema superior ao fordismo. No paradigma eletromecânico, em que este último surge, os custos de controle eram muito elevados. Assim, abrir mão da flexibilidade em prol da produtividade era de fato uma excelente opção e, não por acaso, até o começo dos anos 70, são as empresas fordistas que dominarão o mundo. ${ }^{5}$ Com o decorrer dos anos 70, contudo, o cenário favorável à produção em massa se esgota. Não só estagflação dificulta a exploração de escalas crescentes, como um fato novo - o advento da microeletrônica - reduz drasticamente os custos de controle.

De fato esse é um período em que se processa a miniaturização da eletrônica, possibilitando a constituição de sistemas de controles extremamente potentes, confiáveis e baratos. Com eles, a automação pode ser flexibilizada através do desenvolvimento de máquinas de comando numérico, robôs e sistemas informacionais dos mais diversos. A utilização dessa automação flexível, por sua vez, com o desenvolvimento de softwares amigáveis, tornou-se cada vez mais fácil. O complicado, ou mesmo o impossível, era adaptar as rígidas organizações tayloristas/fordistas, da produção em massa, às características desse novo paradigma. O toyotismo, contudo, não tinha esse problema. ${ }^{6}$

Buscando a produtividade com a manutenção da flexibilidade, o toyotismo casava perfeitamente com a automação flexível. Era como se um fosse feito sob encomenda para o outro. Não havia impasses nem contradições. Com a mão-deobra polivalente e estruturas hierárquicas horizontalizadas, as empresas toyotistas podiam adotar, e de fato adotaram, a automação flexível como um avanço natural da mecanização flexível. No limite, era simplesmente um processo de troca de máquinas e sistemas de controle humano por máquinas de controle microeletrônico muito mais eficientes.

Com a automação flexível, o toyotismo estava fadado a assumir a supremacia nos sistemas produtivos e de fato assim se deu. Mesmo com a relutância de suas estruturas administrativas, com o ameaçador avanço das empresas japonesas, ao final dos anos 80, começo dos 90, todas as grandes empresas ocidentais de montagem foram, de alguma forma, paulatinamente se convertendo ao toyotismo. É com esse novo modelo de organização - hoje também denominado de sistema de produção enxuta - que a indústria automotiva vivencia no Brasil as sua terceira grande onda de investimentos. ${ }^{7}$

\section{A Reconfiguração Espacial}

A superação do modelo de produção em massa, com a ascensão da produção enxuta, não significou apenas uma reconfiguração dos sistemas de montagem. Em função de características intrínsecas à produção enxuta, ela significou também uma profunda reconfiguração na forma como as indústrias se localizam no espaço.

\footnotetext{
4 Para uma análise mais detalhada das técnicas de administração japonesa, ver, entre outros, Aoki (1986), Coriat (1994) e Schonberger (1984).

${ }^{5}$ Ainda que sendo inferior ao fordismo no paradigma eletromecânico, o toyotismo era a opção certa para o Japão. Com ele, e com o mercado interno protegido por barreiras geográficas e institucionais, suas empresas puderam se expandir internacionalmente, explorando as brechas criadas e deixadas pelo próprio fordismo.

${ }^{6}$ Sobre esse ponto, ver Alban (1999, cap.8).

7 O termo produção enxuta foi cunhado por Womack, Jones e Roos no já referido trabalho de 1992.
} 
Na produção em massa - versão GM - a produção de peças e mesmo subconjuntos, em grande medida processa-se em locais distintos da linha de montagem final. A razão para tal é a busca de economias de escala na produção de peças que poderão ser utilizadas em vários produtos. Se isso acontece, por outro lado, a produção de peças e a montagem das mesmas tende a se dar por empresas distintas que, operando via mercado, buscam se aproximar umas das outras, gerando grandes economias de aglomeração. Tem-se, dessa forma, um processo de polarização concentrada que faz com que boa parte da indústria automotiva tenda para uma única região em cada mercado nacional.

A estruturação espacial da produção enxuta, naturalmente, será bastante distinta. Buscando desde os primórdios a produtividade com flexibilidade, a produção enxuta não se dará com a exploração de escalas crescentes. Nesse sentido, para viabilizar o just in time, as empresas japonesas - especialmente a Toyota puderam agregar boa parte de suas respectivas cadeias produtivas em espaços relativamente pequenos e contíguos. Com plantas de peças e montadoras literalmente coladas, os kanbans (cartões de pedidos) podiam transitar facilmente entre as empresas, fazendo com que toda a cadeia integrada respondesse eficientemente às oscilações da demanda final.

Enquanto a produção enxuta se restringiu ao Japão, um país de dimensões bastante exíguas, essa característica espacial parecia não ter maiores impactos na localização das empresas. A partir dos anos 80 , porém, com a entrada das empresas japonesas no mercado americano, tornou-se evidente que a espacialização da indústria automotiva não mais seria a mesma. Implantando-se de maneira integrada, ou seja, com plantas de autopeças dedicadas, as empresas japonesas não precisavam ficar em Detroit, como ocorria com a maioria das empresas americanas. Ao contrário, elas podiam escolher localidades mais propícias, levando em conta custos de matérias-primas e insumos, transportes, mãode-obra e, sobretudo, incentivos fiscais.

A questão dos incentivos fiscais - municipais e estaduais - deve ser ressaltada por que ela, de fato, só ganha relevância com a produção enxuta. $\mathrm{Na}$ produção em massa, como dissemos, quase toda a indústria era levada a uma polarização concentrada, com a qual não havia muito como competir. As vantagens de se localizar no pólo eram tão grandes que praticamente inviabilizavam os incentivos com vistas à relocalização. De outro lado, havia um grave problema de coordenação, já que as empresas não operavam de maneira integrada. Ou seja, não bastava ter a capacidade de relocalizar a montadora ou as fábricas de autopeças, era preciso relocalizar todo o sistema ao mesmo tempo, o que era quase impossível.

Todas essas dificuldades, é claro, desaparecem na produção enxuta. Sendo um sistema que se estrutura em rede, e sob o comando da montadora, ele tende a se deslocar conjuntamente. Nesse sentido, ele não precisa se localizar junto aos pólos tradicionais. No limite, ele pode se localizar em quase qualquer região que detenha uma mínima infra-estrutura básica, já que ele é o seu próprio pólo. Se isso acontece, as montadoras assumem um enorme poder de barganha, estabelecendo um verdadeiro leilão de incentivos fiscais entre as diversas regiões interessadas. Foi exatamente isso o que as montadoras japonesas fizeram ao entrar no mercado americano, sendo logo copiadas pelas européias e, também, pelas próprias americanas na medida em que estas se adaptaram à produção enxuta.

Como se constata no Mapa 1 , se até os anos 70 a grande maioria das plantas americanas se localizava na região de Detroit, no Estado de Michigan, a partir dos anos 80 o processo muda completamente. Apenas uma nova planta opta por esta região, todas as demais se espalham por diversos estados do Meio-Oeste, sem criar nenhuma nova polaridade. No Mapa 2 essa mesma dinâmica pode ser constatada também no caso italiano. Enquanto até os anos 70 todas a plantas se polarizavam em Turim, na região norte da Itália, a partir dos anos 80 elas passam a optar por cidades do centro e do sul do País. 
Como se sabe, um processo muito semelhante a essa dinâmica internacional ocorrerá com a indústria automotiva brasileira. Atraídas para o País em meados dos anos 50, todas as montadoras que aqui se implantam até o final dos anos 60 optaram pela cidade de São Paulo e pela região do $A B C D$, no seu entorno. ${ }^{8}$ Sendo São Paulo o centro da economia cafeeira, que comandou o Brasil entre 1870 e 1930, esta era a região mais desenvolvida e infra-estruturada do País, onde já se concentrava boa parte da industrialização em curso. Naturalmente, o mesmo se deu com o parque metal-mecânico, produtor de autopeças. A indústria automotiva, portanto, irá reforçar o processo de polarização do desenvolvimento econômico no País (Tabela 2).

Mapa 1 Evolução da Indústria Automotiva nos EUA

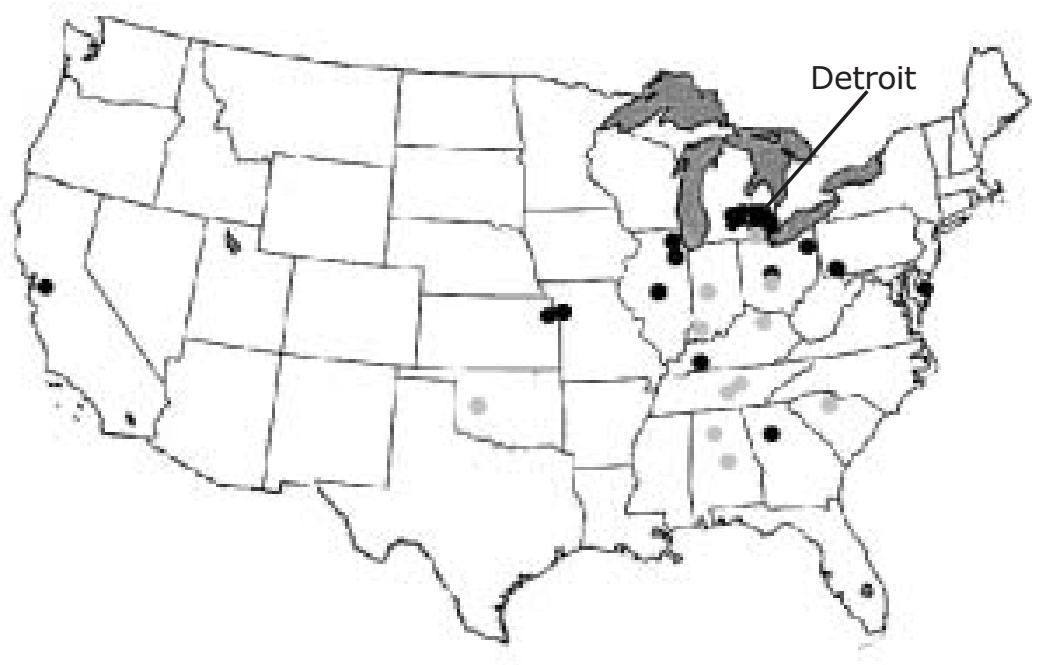

Mapa 2 - Evolução da Indústria Automotiva na Itália

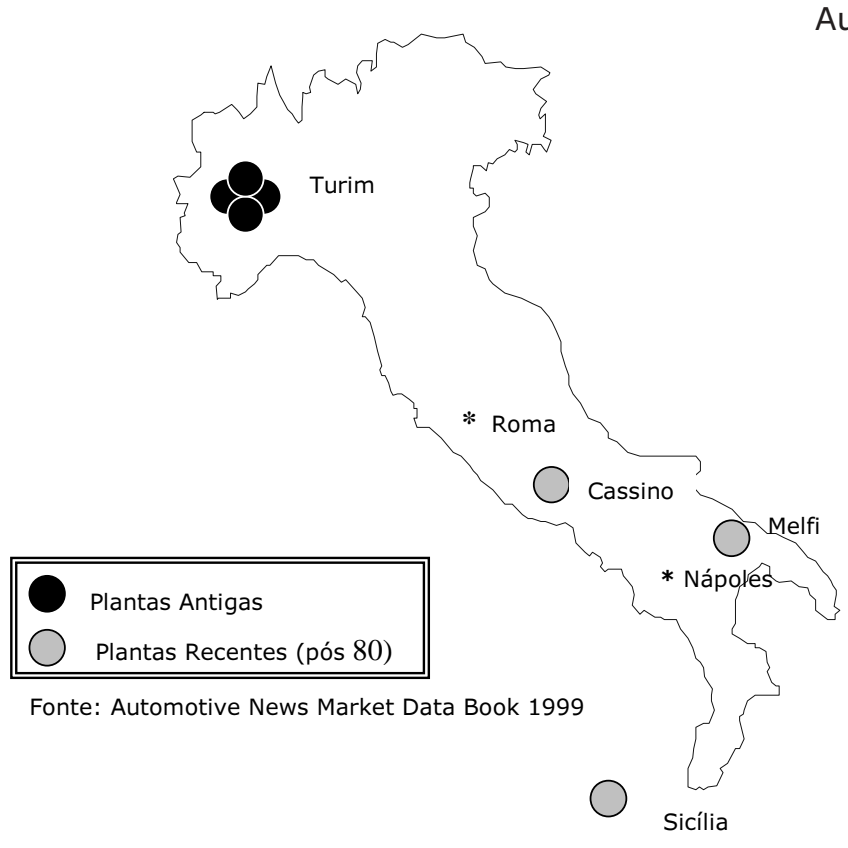

\& Para uma boa análise da dos primórdios da indústria automotiva no Brasil, ver Shapiro (1994) e Almeida (1972). 
Tabela 2 São Paulo/Nordeste - Participação no Valor de Transformação e nos Empregos Industriais 1949 - 1959

\begin{tabular}{lrrrr}
\hline & Bens Duráveis e de Capital & \multicolumn{2}{c}{ Todos os bens } \\
\hline Valor da Transf. Industrial & 1949 & 1959 & 1949 & 1959 \\
- São Paulo & 69,71 & 82,03 & 48,85 & 55,55 \\
- Nordeste & 0,65 & 0,62 & 9,12 & 6,89 \\
Operariado Industrial & & & & \\
- São Paulo & 57,68 & 72,27 & 41,01 & 46,60 \\
- Nordeste & 1,73 & 1,56 & 16,67 & 12,17 \\
\hline
\end{tabular}

Fonte: Cano (1985:105)

Nos anos 70 e 80, na segunda onda de investimentos automotivos, esse processo começa a se modificar, mas muito timidamente. De uma maneira geral, as montadoras e as fabricantes de auto peças já instaladas optam por construir algumas de suas novas plantas no Vale do Paraíba. As mudanças mais relevantes ficam por conta da Volvo e da Fiat, que, chegando ao País com unidades de produção relativamente pequenas, optam por se localizar fora do estado de São Paulo. A Volvo, com uma fábrica de caminhões e ônibus, irá para a Cidade Industrial de Curitiba e a Fiat, com uma fábrica inicialmente de veículos populares, irá para Betim, na Região Metropolitana de Belo Horizonte (Tabela 3).

Tabela 3 Parque Automotivo Brasileiro Implantado até 1980

\begin{tabular}{|c|c|c|c|c|}
\hline Empresa & Estado & Produtos & $\begin{array}{l}\text { Fat. } 1997 \\
\text { (R\$ milhão) }\end{array}$ & $\begin{array}{l}\text { Num. de } \\
\text { Empregos }\end{array}$ \\
\hline Ford & São Paulo & $\begin{array}{l}\text { Veículos de passeio / comerciais } \\
\text { leves/ ônibus }\end{array}$ & 3.934 & 11.183 \\
\hline GM & São Paulo & $\begin{array}{l}\text { Veículos de passeio / comerciais } \\
\text { leves / caminhões }\end{array}$ & 6.650 & 21.411 \\
\hline Merc. Benz & São Paulo & Caminhões / ônibus & 2.607 & 11.360 \\
\hline Scania & São Paulo & Caminhões / ônibus & 900 & 2.922 \\
\hline Toyota & São Paulo & Comerciais leves & 314 & 735 \\
\hline VW & São Paulo & $\begin{array}{l}\text { Veículos de passeio / comerciais } \\
\text { leves / caminhões / ônibus }\end{array}$ & 7.086 & 32.909 \\
\hline Volvo & Paraná & Caminhões / ônibus & 648 & 1.367 \\
\hline Fiat & Minas Gerais & $\begin{array}{l}\text { Veículos de passeio / comerciais } \\
\text { leves }\end{array}$ & 6.265 & 23.908 \\
\hline
\end{tabular}

Fonte: Anfavea e BNDES, montado a partir de Santos e Pinhão (1999:176)

Importante observar que, ainda que optando por estados vizinhos, Paraná e Minas Gerais, a saída de São Paulo não era uma opção trivial. São Paulo não só permanecia como o principal mercado final, como detinha a quase totalidade do parque produtor de autopeças. Dessa maneira, sair de São Paulo significava custos muito mais altos, o que exigia fortes incentivos compensatórios. Esses incentivos ocorreram em ambos os casos, sendo mais marcantes no caso da Fiat por tratar-se de uma planta produtora de veículos. Em linhas gerais, para atrair a Fiat, em meados dos anos 70, o Governo mineiro teve de doar o terreno, investir pesadamente em infra-estrutura, retornar um quarto do ICM gerado, garantir um empréstimo subsidiado de 20 milhões de dólares e ainda participar com 46\% do capital investido (Campolina, 1981). ${ }^{9}$

\footnotetext{
${ }^{9}$ Embora não tão amplos quanto os concedidos à Fiat, os incentivos para atração da Volvo não foram pequenos. Segundo nos foi relatado na pesquisa de campo, o poder público paranaense, além de assegurar a compra de um determinado número de ônibus para o seu programa de transporte urbano, também participou acionariamente do projeto e concedeu gratuitamente o terreno infra-estruturado. Sobre esse ponto, ver também Toso (1995) em sua análise da formação da Cidade Industrial de Curitiba.
} 
Depois da implantação da Volvo ao final dos anos 70, o Brasil passará por toda a década dos 80 , a chamada década perdida, apenas tentando combater a inflação. Esse cenário só será revertido nos anos 90, quando, com uma fixação da taxa de câmbio, a economia brasileira se estabiliza através de uma forte abertura ao comércio internacional. Esse processo, concebido como uma inserção competitiva na globalização, deixou o mercado nacional extremamente atrativo para as importações. No caso da indústria automotiva, contudo, através de uma das poucas ações de política industrial adotadas no período, vinculou-se a importação, com baixas tarifas, ao comprometimento com a produção local. Assim, via o chamado Regime Automotivo, nos anos 90 foram decididas e implantadas uma série de novas unidades montadoras no País. ${ }^{10}$

Como se constata na Tabela 4, entre 1994 e 1997 tem-se a terceira onda de investimentos automotivos, com a decisão e implantação de 10 novas unidades de montagem, a grande maioria delas empreendidas por empresas que ainda não operavam no País. No total, essas unidades representam um investimento nada desprezível de cerca de seis bilhões de dólares e a geração de quase 14,5 mil novos empregos diretos. A maior dessas unidades, no entanto, não se localizará em São Paulo. Ao contrário, à exceção das pequenas unidades da Honda e da Toyota, meras montadoras de CKDs, todas as demais optam por outros estados, o que não é de se estranhar. Sendo concebidas no sistema de produção enxuta, todas tinham grande liberdade de localização. Nesse sentido, a exemplo do ocorrido nos países centrais, estabelece-se, também no Brasil, um intenso leilão com base em incentivos fiscais, mudando por completo a configuração espacial da indústria no País.

Tabela 4 Plantas Novas Decididas entre 1994 e 1997

\begin{tabular}{lllrrr}
\hline Empresa & Estado & Produtos & $\begin{array}{r}\text { Invest. em } \\
\text { US\$ milhão }\end{array}$ & $\begin{array}{l}\text { Capadid. } \\
\text { produtiva }\end{array}$ & \multicolumn{2}{l}{$\begin{array}{l}\text { Empg. Dir. } \\
\text { Previsto }\end{array}$} \\
\hline Iveco/Fiat & Min. Gerais & Com. Leves/caminhões & 240 & 40.000 & 2.000 \\
Merc. Benz & Min. Gerais & Veículos de passeio & 820 & 90.000 & 1.500 \\
Peugeot & R.de Janeiro & Veículos de passeio & 600 & 110.000 & 2.500 \\
Honda & São Paulo & Veículos de passeio & 150 & 20.000 & 400 \\
Toyota & São Paulo & Veículos de passeio & 150 & 15.000 & 350 \\
Renault & Paraná & Veículos de passeio & 1.000 & 100.000 & 2.000 \\
VW/Audi & Paraná & Veículos de passeio & 700 & 120.000 & 1.500 \\
Chrysler & Paraná & Comerciais Leves & 315 & 15.000 & 400 \\
GM & R.G. do Sul & Veículos de passeio & 700 & 140.000 & 1.300 \\
Ford & R.G. do Sul & Veículos de passeio & 1.300 & 150.000 & 2.500 \\
TOTAL & ----------- & ----------------------- & 5.975 & 800.000 & 14.450 \\
\hline
\end{tabular}

Fonte: Anfavea e BNDES, montado a partir de Santos e Pinhão, 1999, p.176.

\section{A Relocalização do Projeto Amazon}

Analisando a nova espacialização da indústria automotiva brasileira, observa-se que a mesma, embora saindo de São Paulo, não se difundiu homogeneamente pelo País. De fato, ao menos até 1997, quase todas as intenções de investimento estavam localizadas abaixo da Região Metropolitana de Belo Horizonte. ${ }^{11}$ Ou seja,

\footnotetext{
10 Segundo vários analistas, a vinda de novas montadoras decorreu, também, da saturação do setor no âmbito internacional, aliado ao grande potencial do mercado local. De fato, enquanto nos Estados Unidos e Europa a relação habitantes por veículo é inferior a dois, no Brasil é superior a dez. Ainda que muito desse potencial não vá se realizar tão cedo, dada a baixa renda per capita e a extrema concentração da renda total, no começo dos anos 90, com o incentivo aos carros populares de até 1000 cc, demonstrou-se a possibilidade concreta para significativas expansões de mercados. Sobre esse ponto, ver Meiners (1999,122:33).

11 O único projeto na Região Metropolitana de Belo Horizonte é, não por acaso, justamente o da Fiat em Sete Lagoas. O da Mercedes fica em Juiz de Fora, na Zona da Mata, bem ao sul do estado.
} 
ao sul do limite superior da estrutura já implantada. Não se trata, é claro, de uma mera coincidência já que, como relatado pela mídia, vários estados do Norte e do Nordeste participaram ativamente do leilão. A opção pelo sul do País, que se expressa de maneira mais marcante nas plantas originalmente propostas para o Paraná e o Rio Grande do Sul, reflete, na verdade, um processo puramente racional engendrado pelo Mercosul.

Concebido em meio à formação de vários blocos comercias no mundo, o Mercosul se transformou na grande estrela dos anos 90. Criando um mercado comum entre Brasil, Argentina, Paraguai e Uruguai, ele era uma possibilidade efetiva de crescimento para as empresas mais competitivas Nesse sentido, a maioria das montadoras que decidiram se implantar no País, ao relegarem São Paulo, naturalmente optaram por estados da região Sul. A percepção desse processo é da maior importância porque ele demonstra que, mesmo na produção enxuta, os incentivos fiscais, embora relevantes, não explicam tudo. Assim, da mesma forma que a Fiat, nos anos 70, não foi para Minas apenas pelos incentivos, nos anos 90 Paraná e Rio Grande do Sul não receberam tantas montadoras apenas pela maior frugalidade de suas burocracias de fomento.

De fato, se no anos 70 a opção da Fiat por Minas pode também ser explicada pela baixa organização sindical, grande disponibilidade de produtos metalúrgicos e siderúrgicos e, sobretudo, por estar a meio caminho de Brasília - na época um dos grandes vetores de crescimento do País -; nos anos 90, a opção por Paraná e Rio Grande do Sul tem muito a ver por serem esses dois estados uma espécie de centro geográfico do Mercosul. Obviamente, ambos os estados têm outras vantagens locacionais, como excelentes padrões de qualidade de vida, alta escolaridade da mão-de-obra e, no caso específico do Rio Grande do Sul, ampla disponibilidade de produtos petroquímicos. O fator mais importante, no entanto, conforme atestam vários estudos, é de fato a localização estratégica frente ao Mercosul. ${ }^{12}$

Interessante observar, paralelamente, que nessa opção pelo Sul as empresas que optam por São Paulo, ou por sua vizinhança imediata, são justamente aquelas recém chegadas ao País e/ou que possuem também uma forte estrutura produtiva na Argentina. Esse é certamente o caso da Honda, Renault, Peugeot e Chrysler que, por serem new comers, têm um interesse preponderante no mercado brasileiro. De outro lado, as empresas que optam por distanciar-se, escolhendo o Rio Grande do Sul, são aquelas que já possuem uma forte estrutura produtiva no País - Ford e GM - e logo demonstram interesse mais marcante nos demais mercados do Mercosul. ${ }^{13}$

Em que pese toda essa racionalidade no espraiamento da indústria automotiva em direção ao Sul, no começo de 1999, a Ford, após uma acirrada divergência fiscal com o Governo recém eleito do Rio Grande do Sul, suspenderia o projeto naquele estado, transferindo-o, meses depois, para a Bahia. ${ }^{14} \mathrm{Se}$ as razões da suspensão do projeto são aparentemente claras, afinal o novo Governo rompeu contratos e acordos estabelecidos pelo seu antecessor, a opção pela Bahia é surpreendente. Situando-se no Nordeste, a Bahia está muito longe de ser uma boa localização para um projeto que visa, ou ao menos visava, o Mercosul.

Durante todo o processo de análise da relocalização da Ford, esse foi um aspecto completamente ignorado. Por ser o Rio Grande do Sul um estado governado pelo PT e a Bahia governada pelo PFL - e o PFL do senador Antônio Carlos Magalhães - toda a discussão acabou se dando em torno de questões políticas e fiscais. Nesse sentido, tendeu-se a ver a opção pela Bahia em razão do viés "liberal" do estado, reforçado por um amplo programa de incentivos fiscais e de obras infra-estruturais. Essa visão, no entanto, não parece ser correta. Não que esses fatores não sejam importantes e reais - a questão é que até 1999 eles não foram suficientes para trazer nenhuma montadora para o estado. A esperada vinda da Hyundai e da Asia Motors, como se sabe, acabou não se concretizando.

\footnotetext{
12 Sobre esse ponto ver, entre outros, Zawislak et al. (1999) e Santos e Pinhão (1999).

${ }_{13}$ Note-se que os casos da Toyota e da Mercedes Benz não constituem verdadeiras exceções a essa regra, já que se trata também de empreendimentos pioneiros no segmento de veículos de passeio. ${ }^{14}$ Além de transferir, a Ford irá também ampliar o seu projeto, passando-o de 150 mil unidades/ano para 250 mil.
} 
Ao mesmo tempo, deve-se notar que se o Rio Grande do Sul tinha um viés "anti-empresa", Santa Catarina e Paraná eram claramente mais liberais e com programas de incentivos - também vigorosos - tentaram, sem sucesso, atrair a Ford. Considerando-se esses últimos aspectos, e face a todo o contexto anterior, pode-se argumentar que a desistência do projeto no Rio Grande do Sul reflete muito mais do que um mero problema político-fiscal com o PT gaúcho. Ao que parece, trata-se de uma decisão estratégica mais ampla, de abandonar o Sul do País. ${ }^{15}$ Essa hipótese faz muito sentido se considerarmos as mudanças recentes na política econômica brasileira e seus impactos no Mercosul. Nos referimos aqui à liberação do câmbio ocorrida no início de 1999.

Estabelecido em 1992, o Mercosul viverá sua fase áurea de desenvolvimento entre 1994 e 1997. Nesse período, quando o Brasil estabiliza sua economia com uma taxa de câmbio sobrevalorizada, a Argentina pôde manter o seu sistema de currency board com paridade fixa sem maiores conflitos. Com uma balança comercial muito favorável para com o Brasil, ela não só sustentava parte do seu crescente déficit com o restante do mundo, como, ao mesmo tempo, justificava o acesso a empréstimos internacionais. Enquanto isso, no Brasil, com os recursos direta ou indiretamente gerados pelas privatizações, sustentava-se um déficit comercial também crescente. A saída para essa dinâmica, claramente inviável a longo prazo, estaria num esperado choque de produtividade a ser gerado pela abertura das economias, pelas privatizações e pelo próprio Mercosul.

Com o choque de produtividade, Brasil e Argentina, os dois principais parceiros do sistema, reequilibrariam suas balanças comerciais, viabilizando o crescimento integrado e auto-sustentado de suas economias. O choque de produtividade, no entanto, acabou não se dando de modo adequado e, assim, após as crises asiática e russa, em 1997/98, o Brasil acabou sendo forçado a liberar a taxa de câmbio. A Argentina, como se sabe, não seguiu o mesmo caminho. Por ter gerado todo um complexo sistema financeiro interno atrelado ao dólar, optou por resistir com a paridade fixa. Como não poderia deixar de ser, isso resultou em déficits potencialmente crescentes na balança comercial e em grandes dificuldades no acesso a recursos internacionais. Numa dinâmica como essa o Mercosul, é claro, não podia avançar. ${ }^{16}$

Se o Mercosul não podia avançar, o Brasil, por outro lado, com a liberação cambial, tornava-se apto para avançar sozinho. Claro que isso não teria como acontecer de imediato. Com a crise da energia interna e a agudização da crise internacional não era possível, naquele momento, nenhuma retomada acelerada do crescimento. As exportações, contudo, já retomavam o crescimento e, com a taxa de câmbio flutuante, vencido o auge dessa dupla crise, os juros internos tenderiam a cair, possibilitando a expansão paralela da demanda interna. Eram e ainda são - expressivas, portanto, as chances do Brasil retomar, nos próximos anos, um crescimento acelerado e sustentado de sua economia. ${ }^{17}$

Deve-se observar que todo esse potencial de crescimento é bastante distinto do apresentado pelo País até os anos 70. Já não se trata de crescer voltado

\footnotetext{
${ }^{15}$ Interessante observar que a planta da GM, recém inaugurada no Rio Grande do Sul, já vem sendo considerada como um possível grande equívoco. Sobre esse ponto, ver o sugestivo artigo da Business Week: "Super Factory or Super Headache" (31/07/00).

${ }^{16}$ De fato, desde o começo de 1999 o Mercosul atravessou sucessivos reveses. Tendo como única "saída" a recessão interna para conter a expansão dos déficits, a Argentina buscou amenizar a crise estabelecendo salvaguardas unilaterais contra a importação de produtos brasileiros em diversos setores. Esse processo foi naturalmente se agravando, até que, ao final de 2001, a Argentina abandonou a paridade fixa no ápice de uma crise sócio-econômica sem precedentes.

17 Cumpre ressaltar que as chances, embora expressivas, continuam sendo apenas chances. Ou seja, a retomada sustentada não está de todo assegurada. Ainda que a fragilidade financeira interna possa, em tese, ser enfrentada por uma taxa de câmbio mais desvalorizada, e que a crise energética tenda a ser superada (se já não o foi), existem hoje sérias indefinições internacionais. Será bem sucedida a guerra contra o terrorismo? O que acontecerá com a Bolsa de Nova York? E a Argentina? Essas são questões que podem inviabilizar qualquer estratégia de crescimento articulado.
} 
ou puxado pela substituição de importações e pelos grandes projetos estatais. 0 carro-chefe hoje são, de fato, as exportações e as exportações para o mundo e não apenas para o Mercosul. ${ }^{18}$ Se é assim, em vários grandes projetos, ao sair de São Paulo, não faz mais sentido a opção pelo Sul do país. Muito mais interessante é o deslocamento em direção ao Nordeste, onde se tem uma maior proximidade com os grandes mercados da Europa, México e Estados Unidos. Ao que tudo indica, foi exatamente essa a lógica que comandou o processo de relocalização e expansão da Ford. ${ }^{19}$

Naturalmente, considerar que existe hoje uma maior racionalidade locacional na opção pela Bahia/Nordeste, não significa dizer que se deva, ou se possa, abrir mão de uma política de incentivos fiscais e infra-estruturais para a atração de investimentos. Ainda que as exportações passem a ser o carro-chefe em termos qualitativos, no agregado o mercado interno será sempre o mais importante em termos quantitativos. Assim, sendo esse mercado ainda muito polarizado em São Paulo e seu entorno, e na ausência de uma política nacional de desenvolvimento, os incentivos regionais e estaduais permanecem importantes. Eles, entretanto, já não precisam ter a magnitude que tiveram no passado.

\section{REFERÊNCIAS BIBLIOGRÁfICAS}

ALBAN, M. (1998) Crescimento sem Emprego: o desenvolvimento capitalista e sua crise contemporânea à luz das revoluções tecnológicas. Salvador: Casa da Qualidade.

ALMEIDA, J. (1972) A Implantação da Indústria Automobilística no Brasil. Rio de Janeiro: Fundação Getúlio Vargas.

AOKI, M. (1990) "Toward an Economic Model of the Japanese Firm", Journal of Economic Literature, vol. XXVI, n. 1.

AUTOMOTIVE NEWS MARKET DATA BOOK (1999) North American car assembly plants. Maio.

BUSINESS WEEK (2000) "Super Factory or Super Headache", 31 de julho.

CANO, W. (1985) Desequilíbrios Regionais e Concentração Industrial no Brasil, 19301970. São Paulo: Editora da UNICAMP.

CORIAT, B. (1994) Pensar pelo Avesso: o modelo japonês de trabalho e organização. Rio de Janeiro: Revan.

FORD, H. (1926) "Mass Production", in Encyclopedia Britannica, 13a edição, supl. vol.2.

FORD, H. (1954) "Minha Vida e Minha Obra" in H. Ford, Os Princípios da Prosperidade. Rio de Janeiro: Brand.

MEINERS, W.E.M.A. (1999) Implantação da indústria automobilística e os novos contornos da região de Curitiba. Dissertação de Mestrado, UFPR.

NASSIF, L. (1999) "É Hora de Discutir o "Latino". Folha de São Paulo, 11 de agosto. PFEIFER, I., VILARDAGA, V. e VILELLA, A. (2000) "Suspenso acordo automotivo do Mercosul", 8 de agosto.

\footnotetext{
18 Como observa Vilardaga, em relação ao setor automotivo: "Desde a desvalorização cambial (...) as montadoras (...) mudaram completamente os seus planos de exportação. A estratégia de trocas comerciais com a Argentina foi deixada de lado em favor de outros destinos. A perda de negócios no Mercosul é compensada pelo aumento do volume de vendas (...) para outros mercados (07/07/00). 19 Não por acaso, a expectativa é de que o projeto Amazon venha dedicar ao mercado externo cerca $30 \%$ de sua capacidade produtiva.
} 
PFEIFER, I., VILARDAGA, V. e VILELLA, A. (2000) "Mercosul tenta reerguer acordo automotivo", 14 de agosto.

SALGUEIRO, S. (2000) "Autopeças brasileiras conquistam mercado externo", 8 de março.

SANTOS, A.M. e PINHÃO, C.M. (1999) "Pólos Automotivos Brasileiros". Rio de Janeiro: BNDES.

SCHONBERGER, R.J. (1984) Técnicas Industriais Japonesas: nove lições ocultas sobre a simplicidade. São Paulo: Pioneira.

SHAPIRO, E. (1994) Engines of Growth: the state and transnational auto companies in Brazil. Cambrodge: University of Cambrige Press.

VILARDAGA, V. (2000) "Montadoras voltam aos seus melhores momentos", 7 de julho.

WOMACK, J.P., JONES, D.T., e ROOS, D. (1992) A Máquina que Mudou o Mundo. Rio de Janeiro: Campus.

ZAWISLAK, P. et al. (1999) Diagnóstico Automotivo. Porto Alegre: UFRGS/NITEC. 